\title{
JOB STRESS, WORKLOAD, EXERCISE HABITS AND METABOLIC SYNDROME IN ACADEMIC PERSONNEL AT AIRLANGGA UNIVERSITY
}

\author{
Ratih Damayanti, Ratnaningtyas Wahyu Kusuma Wardhani, Berliana Devianti Putri and Indah Lutfiya \\ Health Department, Faculty of Vocational, Universitas Airlangga
}

Corresponding author: Ratih Damayanti

Email: ratih.damayanti@vokasi.unair.ac.id

\begin{abstract}
Every human individual must have experienced stress. Especially in situations or conditions with high stressors, one of which is the work factor. Job stress can have an effect on the occurrence of health problems, one of them is metabolic syndrome. The purpose of this study was to analyze the relationship between work stress, workload, exercise habits and metabolic syndrome in employees in Offices (case study at Airlangga University). This study was an observational analytic study with a cross-sectional research design. The population of this research is all education staff I academic staff, namely in the finance, human resources, infrastructure, academic, student, quality assurance, information system units, dean secretariat, laboratory staff and receptionist at Airlangga University. The sample size involved in this study was 70 people. A significant factor influencing the occurrence of metabolic syndrome is work stress and exercise habits. Meanwhile, the factors that influence the occurrence of work stress are age and workload. Each age increases by 1 year, the risk of work stress increases 1,126 times. Increasing the level of work stress increases the risk of developing metabolic syndrome by 1,146 times. The less regular exercise is, the risk of metabolic syndrome increases by 58 times. One of the efforts to solve the problem of metabolic syndrome are by exercising regularly and managing stress well. In addition, given the opportunity to exercise in between work and the presence of sports facilities in the work area can help reduce the risk of getting metabolic syndrome and work stress.
\end{abstract}

Keywords: work stress, workload, exercise habits, metabolic syndrome, academic staff

\section{INTRODUCTION}

Every individual must have experienced stress. Especially in situations or conditions with high stressors, one of which is the work factor. The depression rate in Indonesia reaches $6.1 \%$ while in East Java province is slightly below the Indonesian figure which is $4.5 \%$. Emotional disturbances were higher than the depression rate at $9.8 \%$ while in East Java province it was $6.8 \%$. More women experience depression and emotional disorders ${ }^{1}$.

Job stress is an important issue that is always discussed in any organization or agency. Job stress or also referred to as potential psychological hazards are potential hazards arising from unclear / inaccurate roles, role conflicts, qualitative workloads, quantitative workloads, career development, and responsibilities to others ${ }^{2}$. Workload is something that arises because of the interaction between the demands of work environment tasks which are used as workplaces, skills, behaviors and perceptions of workers ${ }^{3}$. There are several things that affect the workload, including workload due to external factors. Workload due to external factors in question are tasks or everything related to the physical worker, such as work stations, work space layout, work tools and facilities, working conditions or terrain, and work attitudes. Work hours, rest periods, work shifts, wage systems, responsibilities and authority are the efforts made by an organization to control the work stress of employees. Factors of work environment which includes physical, chemical, biological, and psychological. In addition there are internal factors which include somatic factors which include sex, age, body size, and nutritional status. According to Tarwaka, psychological factors that influenced the occurrence of work stress include motivation, perception, trust and job satisfaction ${ }^{3}$.

Depression is associated with an increased risk of metabolic syndrome which contributes to poor cardiovascular health as much as 1.5 times higher in individuals with depression ${ }^{4}$. Job stress is a significant predictor of the component of metabolic syndrome in radiologists ${ }^{5}$. Another study states that workers who are exposed to work stress for more than 14 years and more than 3 stress exposures have twice the risk of experiencing metabolic syndrome. There are several factors that influence metabolic syndrome, namely insulin resistance, age, work stress, heredity, food consumption patterns, and lifestyle $^{6-10}$. Physical activity can prevent central obesity. In addition, physical activity carried out at least 30 minutes per day can improve heart and blood vessel health ${ }^{11-12}$.

Metabolic syndrome is a collection of risk factors for heart attack namely diabetes and increased blood glucose during fasting, abdominal obesity, high blood cholesterol and high blood pressure ${ }^{13}$. Risk factors for metabolic syndrome include central obesity, dyslipidemia (high triglyceride levels); high-density lipoprotein / low HDL levels, 
high blood pressure, insulin resistance (high fasting glucose levels), protombosis and proinflammatory conditions (high fibrinogen levels; high C-reactive protein / CRP levels). The diagnosis of metabolic syndrome can be established if there are three or more risk factors ${ }^{14}$.

Riskesdas from Kementerian Kesehatan Republik Indonesia showed there was an increase in the prevalence of hypertension patients from 2013 to 2018 , from $25.8 \%$ to $34.1 \%$. Central obesity sufferers also increased in the period 2013-2018, amounting to $26.6 \%$ to $31.0 \%{ }^{1}$. Population with high cholesterol level reaches $7.6 \%$ with the characteristic that urban population has a higher percentage of experiencing degenerative diseases than urban population. In addition, women are also more at risk of developing hypertension, central obesity and hypercholesterolemia than men. The age factor also determines that as we age, the risk of hypertension, central obesity and hypercholesterolemia also increases ${ }^{1}$.

The level of work stress of lecturers and education staff in one of the faculties at Airlangga University shows that most of them are at a moderate level $(72.84 \%)$ and some even experience high levels of stress $(14.81 \%)^{15}$. Therefore, there is a need for further research and a broader scope for the work stress of academic staff at Airlangga University, especially if it is linked to its impact on health, one of which is metabolic syndrome. The purpose of this study was to analyze the relationship between work stress, workload, exercise habits and metabolic syndrome in employees in Offices (case study at Airlangga University).

\section{METHODOLOGY}

This research was an observational analytic with a cross-sectional design. The population of this researchwas all academic administration staffs at Faculty of Public Health and Faculty of Vocational, Universitas Airlangga Surabaya. Theywork in finance, human resources, infrastructure, academic, quality assurance, information system units, secretariat of dean, laboratory staff, receptionist, etc.Sampling was simple random sampling and obtained 70 staffs.

This research used primary data which divided into 2 stages,ie. filling the questionnaire for independent variable; and measure the waist circumstance, blood glucose, and blood cholesterol for dependent variable. The independent variables were level of job stress, mental workload, and exercise habit. The questionnaire of the level of job stress was compiled based on the form of the Republic of Indonesia Regulation No. 5 of 2018. Then, the questionnaire of mental workload was compiled based on the NASA-TLX form. Last, the questionnaire ofexercise habit was compiled based on various literature.
The level of job stress was identified by 6 sources of stress in the workplace such as role impropriety, role conflict, quantitative overload, qualitative overload, career development, and responsibility towards others. Job stress questionnaire uses a Likert scale with a scale of 1 7 (the greater the value the greater the stress level). Interpretation of results is $\leq 9$ (mild stress risk level), score 10-24 (moderate stress level) and score> 24 (severe stress level).

Mental workload was identified by5 (five) indicators, ie: (1) Physical Demand, (2) Temporal Demand, (3) Performance, (4) Effort, and (5) Frustration Level. The assessment of workload scores starts by weighting to get the Sources of Load value. This is done by giving questionnaires to research subjects that contain 15 pairs of indicators. Subjects were required to choose one (by means of a circle) from the indicators of each pair, which was felt to put more strain on work. The results of the selected indicators are tallyed to get the weight of each indicator. After that, Magnitude of Load is calculated, which gives a rating of five indicators. Subjects were asked to provide a response by marking on a predetermined scale range. After getting a rating, a Weighting and Averaging Procedure is performed, which is calculating the average Weighted workload (WWL) by multiplying the Weight by Rating.

The exercise habit was identified by categorizing into 2 , namely routine and non-routine. Staff who exercise more than once a week are included in the routine category while those who exercise only once a week or twice a week or more are included in the non-routine category. The next step was measure the waist circumstance, blood glucose, blood cholesterol, and blood pressure. All study subjects were completed with an informed consent sheet containing consent for being a research subject and willing to take blood to measure fasting blood glucose and total cholesterol levels. While blood pressure data was done using a blood pressure monitor.

SPSS 17.0 and Lisrel for student was used for data analysis. A multivariable logistic regression model was created to examine the causal association between independent variables and metabolic syndrome using Multiple Logistic Regression with $a=5 \%$. In addition, the researcher examines the strongest indicator in constructing work stress using outer loading and Cronbach' alpha with Lisrel for student application.

\section{RESULTS}

Academic staff in universities both lecturers and employees must have experienced work stress. It could be occurred because of the double workload that is often given to accademic staff. Additional task that are not in accordance with the duties of 
academic staff are always given by each worker. This made workers such as academic staff could experience work stress due to excessive tasks than main task. In addition, the working hours that has been given is from 7:30 AM to 04:00 PM with various level activities such as serving students and lecturers in terms of correspondence, meeting, help the quality assurance process, scheduling lectures and do other administrative tasks. Due to long working hours and various work activities carried out by academic staff, it makes them rarely exercise. Most academic staff have the opportunity to exercise every Friday which is implemented by the faculty as a physical fitness program.
In this study, age, gender, work unit and burden did not influence the occurrence of metabolic syndrome. Significant factors affecting the occurrence of metabolic syndrome are work stress and exercise habits (Table 1). In this study, respondents who are categorized as routine exercise are respondents who exercise more than once a week. Whereas respondents who are categorized as non-routine exercising are respondents who exercise once a week, several times a month and have never exercised at all. Respondents who regularly exercise mostly exercise with a duration of 30-45 minutes at 58\%. The rest exercised for less than 30 minutes by $29 \%$ and more than 45 minutes by $13 \%$.

Table 1. Analysis of Respondents Characteristics, Job Stress, Workload, Exercise Habits and Metabolic Syndrome

\begin{tabular}{|c|c|c|c|c|c|c|}
\hline \multirow{2}{*}{ Variables } & \multicolumn{3}{|c|}{ Metabolic Syndrome, n (\%) } & \multirow{2}{*}{$x^{2}$} & \multirow{2}{*}{ df } & \multirow{2}{*}{$p$} \\
\hline & Yes & No & Total & & & \\
\hline \multicolumn{7}{|l|}{ Age } \\
\hline$<40$ years & $7(24.1)$ & $20(48.8)$ & $27(38.6)$ & 3.375 & 1 & 0.066 \\
\hline$\geq 40$ years & $22(75.9)$ & $21(51.2)$ & $43(61.4)$ & & & \\
\hline \multicolumn{7}{|l|}{ Gender } \\
\hline Male & $13(44.8)$ & $25(61.0)$ & $38(54.3)$ & 1.193 & 1 & 0.275 \\
\hline Female & $16(55.2)$ & $16(39.0)$ & $32(45.7)$ & & & \\
\hline \multicolumn{7}{|l|}{ Division } \\
\hline $\begin{array}{l}\text { HRD and Finance } \\
\text { Academic }\end{array}$ & $6(20.7)$ & $9(22.0)$ & $15(21.4)$ & & & \\
\hline Facilities & $5(17.2)$ & $6(14.6)$ & $11(15.7)$ & & & \\
\hline Infrastructure & $5(17.2)$ & $10(24.4)$ & $15(21.4)$ & 4.306 & 5 & 0.517 \\
\hline Department Staff & $9(31.0)$ & $8(19.5)$ & $17(24.3)$ & & & \\
\hline Lab assistant & $0(0.0)$ & $4(9.8)$ & $4(5.7)$ & & & \\
\hline Others & $4(13.8)$ & $4 \quad(9.8)$ & $8(11.4)$ & & & \\
\hline \multicolumn{7}{|l|}{ Workload } \\
\hline Very low & $0 \quad(0.0)$ & $1 \quad(2.4)$ & $1 \quad(1.4)$ & & & \\
\hline Low & $4(13.8)$ & $6(14.6)$ & $10(14.3)$ & & & \\
\hline Intermediate & $15(51.7)$ & $19(46.3)$ & $34(48.6)$ & 0.953 & 4 & 1.000 \\
\hline High & $8(27.6)$ & $12(29.3)$ & $20(28.6)$ & & & \\
\hline Very high & $2(6.9)$ & $3 \quad(7.3)$ & $5(7.1)$ & & & \\
\hline \multicolumn{7}{|l|}{ Job stress level } \\
\hline Mild & $3(10.3)$ & $6(14.6)$ & 9 (12.9) & & & \\
\hline Medium & $20(69.0)$ & $35(85.4)$ & 55 (78.6) & 9.131 & 2 & $0.009^{x}$ \\
\hline Severe & $6(20.7)$ & $\begin{array}{ll}0 & (0.0)\end{array}$ & $6(8.6)$ & & & \\
\hline \multicolumn{7}{|l|}{ Exercise Habits } \\
\hline Routine & $2(6.9)$ & $18(43.9)$ & $20(28.6)$ & 9.657 & 1 & $0.002^{*}$ \\
\hline Non routine & $27(93.1)$ & $23(56.1)$ & $50(71.4)$ & & & \\
\hline
\end{tabular}

*Significant < 0.05 with Multiple Logistic Regression

However uniquely, the factors that influence the occurrence of work stress are age and workload (Table 2). It can be said that the actual workload does not affect the occurrence of metabolic syndrome but directly affects the occurrence of work stress. Work stress is what causes the occurrence of metabolic syndrome. There are several conditions that cause work stress, including the existence of role conflict, qualitative workload, qualitative workload, career development, responsibility towards people, and role impropriety. Based on Table 3, it is found that all the sources of job stress. The job stress was constructed by role conflict, qualitative workload, quantitative workload, career development, responsibility towards people, and imprecision. All components had cronchbach's alpha value $0.925(>0.700)$, it means that all components of sources of job stress developed job stress. However, the most powerful of the six components is role conflict followed by career development. An overview of the models that constitute or cause of metabolic syndrome could be seen at figure 1 . 
Table 2. Risk Factors of Job Stress

\begin{tabular}{lccc}
\hline \multicolumn{1}{c}{ Independent Variables } & Coeff. & p-value & $\mathrm{Cl}(95 \%)$ \\
\hline Age & 0.234 & $0.000^{*}$ & $0.150-0.318$ \\
Workload & 0.106 & $0.001^{*}$ & $0.043-0.169$ \\
\hline
\end{tabular}

${ }^{*}$ significant < 0,05 with Multiple Logistic Regression

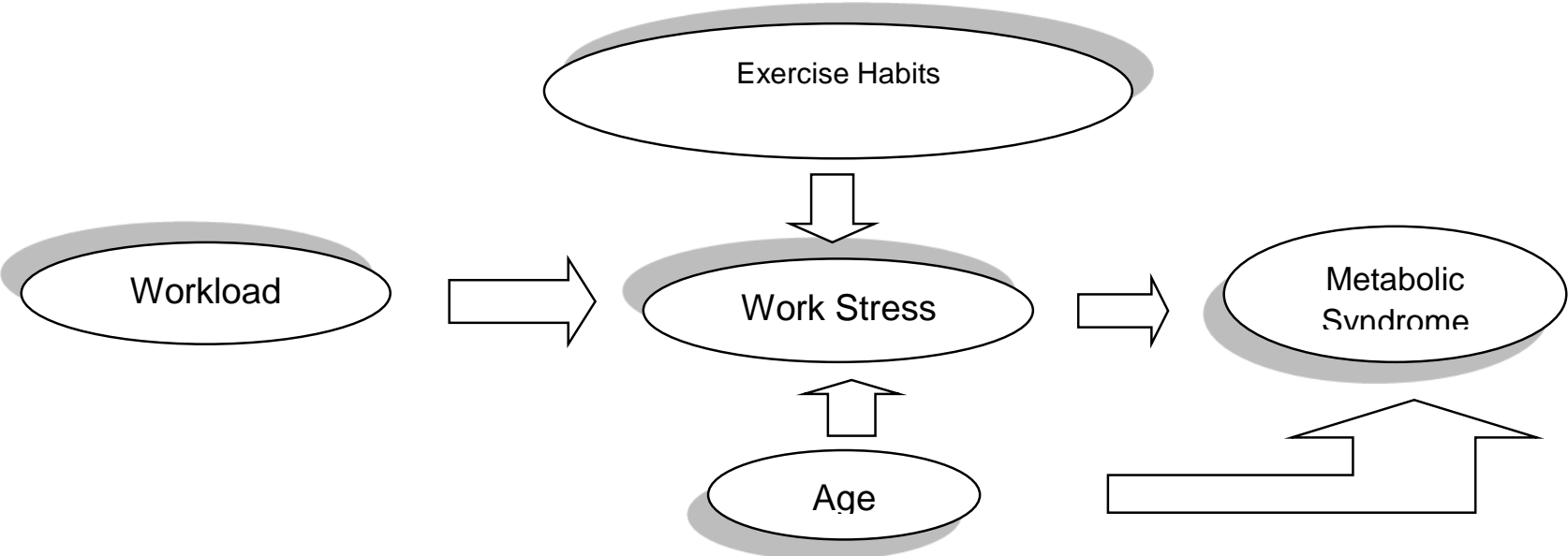

Figure 1: Association between Work Stress, Workload, Exercise Habits, Age and Metabolic Syndrome

Table 3. Sources of Job Stress (Stressors)

\begin{tabular}{lcc}
\hline Source of Job Stress (Stressors) & Outer Loading & Cronbach's Alpha \\
\hline Role conflict & $0.899^{*}$ & \\
Qualitative Workload & $0.862^{*}$ & \\
Quantitative Workload & $0.873^{*}$ & 0.925 \\
Career development & $0.879^{*}$ & \\
Responsibility towards people & $0.730^{*}$ & \\
Imprecision & $0.860^{*}$ & \\
${ }^{*}$ Outer Loading $>0,700$ with Lisrel for Student & &
\end{tabular}

\section{DISCUSSION}

Metabolic syndrome is one of the most important health problems in the world. Increased prevalence rates also have an impact on developing countries including the Asia-Pacific region ${ }^{16}$. An increase of $82 \%$ worldwide, obesity played a role in the period $1990-2010^{17}$. The potential distribution of the prevalence of metabolic syndrome which can vary between provinces, and ethnicities in community groups such as in Indonesia. Differences in demographic factors in each group such as gender average age, ethnic groups, and geographic factors are factors for the occurrence of metabolic syndrome ${ }^{18}$. With research related to metabolic syndrome in special workers can be beneficial as a data bank to be able to prevent the spread of the disease.
In this study, the incidence of metabolic syndrome can also occur in those workers who are in the college environment. The work environment that demands them to work on performance targets can be a factor triggering the emergence of work stress that can cause metabolic syndrome. One of the triggers for stress or the so-called stressor in this study is the workload both quantitatively (in terms of the amount or number of loads) and qualitative (the level of difficulty in completing tasks given by the leadership). In addition to the existence of role conflict, role impropriety and lack of career development and responsibility towards others makes the cause of work stress. However, in this study the most dominant stressors are role conflict, career development and role imprecision.

Roles in the organization of lecturers and education personnel are divided into 3 categories, 
namely ambiguous roles, role conflicts and responsibilities to whom (superiors in the organization). Ambiguous roles and role conflicts are two forms of role stress experienced by a worker. Roles in organizations that are mostly low in lecturer groups can cause moderate work stress. While most of the role of academic staff in a low level of organization can cause work stress at a moderate level as well. The role in the organization significantly influences the occurrence of work stress. But because the role in the organization is low, this variable can contribute to work stress. Academic staff (administration in study programs, academic, financial and laboratory and other supporting) is an important element in a system that is in the university other than lecturers. Academic staff certainly have workloads that are not the same as lecturers. Increasing workload, especially those not related to the main task in the work unit, can actually cause work stress. In addition, the issue that is no less important is that an academic staff also receives orders from 1 or more superiors (including direct superiors). Causing a role conflict ${ }^{15}$.

Stress related to depression, stressors from the environment or perceived stress (subjective) is associated with increased secretion of neurohormonal factors. Genetic variations in stressors and the presence of stressors from the environment can cause the body's response, one of which is the secretion of the hormone cortisol. This cortisol hormone which plays a role in the occurrence of metabolic disorders such as increased triglycerides, decreased HDL levels, an increase in blood pressure and the presence of insulin resistant. It seems to be known that an individual who responds to stress will affect his physical condition (physical onset of illness) ${ }^{19,20}$. A study also showed that there was an increase in cortisol and normetanephrine metabolites in urine, lower heart rate variability (HRV) and an increase in interleukin- 6 and C-reactive protein in cases of metabolic syndrome ${ }^{21}$. However, this study was not examined further to the level of hormones and metabolites.

Another clinical review states that patients with metabolic syndrome show hyperactivation of the hypothalamic-pituitary-adrenal (HPA) axis which causes an increase in the circulation of the hormone cortisol. Increased cortisol circulation can increase visceral fat accumulation. A study proves that the presence of hypercortisol contributes to pathogenesis in someone who has metabolic syndrome. Weight loss can normalize cortisol circulation and increase insulin resistance ${ }^{22-24}$.

In addition to stress factors from respondents lack of physical activity can affect the occurrence of metabolic syndrome. In this study it was found that those who did not perform physical activity at all had 58 times the risk of experiencing metabolic syndrome. In a study stated that metabolic syndrome can be influenced in addition to increasing age, critical position, work is also influenced by physical activity. Physical activity that is less than once a week can significantly increase the occurrence of metabolic syndrome while physical activity carried out routinely more than twice a week can reduce the occurrence of metabolic syndrome25. Research that has been done about physical activity found that the use of leisure time for physical activities such as walking can also reduce the severity of metabolic syndrome ${ }^{26}$.

In this study, the incidence of metabolic syndrome can also occur in those workers who are in the college environment. The work environment that demands them to work on performance targets can be a factor triggering the emergence of work stress that can cause metabolic syndrome. The type of work that can cause stress is a type of work that is related to time, work disruption and the complexity of a job. One of the triggers for stress or the so-called stressor in this study is the workload both quantitatively (in terms of the amount or number of loads) and qualitative (the level of difficulty in completing tasks given by the leadership). In addition to the existence of role conflict, role impropriety and lack of career development and responsibility towards others makes the cause of work stress. However, in this study the most dominant stressors are role conflict, career development and role imprecision. Roles in the organization of lecturers and education personnel are divided into 3 categories, namely ambiguous roles, role conflicts and responsibilities to whom (superiors in the organization). Ambiguous roles and role conflicts are two forms of role stress experienced by a worker. Roles in organizations that are mostly low in lecturer groups can cause moderate work stress. While most of the role of academic staff in a low level of organization can cause work stress at a moderate level as well. The role in the organization significantly influences the occurrence of work stress. But because the role in the organization is low, this variable can contribute to work stress. Academic staff (administration in study programs, academic, financial and laboratory and other supporting) is an important element in a system that is in the university other than lecturers. Academic staff certainly have workloads that are not the same as lecturers. Increasing workload, especially those not related to the main task in the work unit, can actually cause work stress. In addition, the issue that is no less important is that an academic staff also receives orders from 1 or more superiors (including direct superiors) ${ }^{15}$.

Apart from the type of work, environmental factors such as exposure to physical and verbal violence at work and workers directly involved in witnessing and experiencing can be a small exposure to stress at work ${ }^{35}$. Work environment 
factors also have a role in causing stress factors at work. Stress factors at work are found in all workplaces. The type of work in the field to indoors has a risk for work stress factors. A number of cohort studies have been carried out on workers in the field such as the police, manufacturing plant workers, health workers in hospitals and teaching staff in the faculty area. From the results of studies that have been conducted which state that work stress factors have the potential for metabolic syndrome to occur in workers ${ }^{35}$. However, a study was found stating that there was no significant relationship between work stress and metabolic syndrome. In that study, there was no significant relationship between work stress and metabolic syndrome, but there were still many metabolic syndrome problems found in health workers. The problem of work stress is not always found to be the causative factor in the workplace, and has different levels ${ }^{36}$

There are demands or performance targets faced by respondents and there are not many opportunities to exercise in this study associated with the occurrence of metabolic syndrome. Rare physical activity (sports) significantly influences the occurrence of metabolic syndrome. This is certainly a direct or indirect influence. Most respondents in this study claimed to rarely do sports. Respondents who routinely exercise with varying duration are significantly different from the condition of respondents who are not routine or have never even exercised the incidence of metabolic syndrome.

Adults aged 18-64 must do moderate intensity aerobic physical activity for at least 150 minutes throughout the week or do at least 75 minutes of high intensity aerobic physical activity throughout the week or an equivalent combination of moderate and strong intensity activity. To improve health benefits, adults must increase moderate-intensity physical aerobic activity up to 300 minutes per week, or engage in 150 minutes of high-intensity aerobic physical activity per week, or an equivalent combination of moderate and strong intensity activities. Muscle strengthening activities must be done by involving the main muscle groups on 2 days or more a week. There are several ways to collect a total of 150 minutes per week. The concept of accumulation refers to meeting the goal of 150 minutes per week by doing activities in several shorter battles for at least 10 minutes each, spreading throughout the week then adding together the time spent during each of these battles: e.g. 30 minutes of moderate intensity of activity 5 times per week. Evidence of acute effects on biomedical markers shows the benefits of doing routine physical activity throughout the week (such as 5 or more per week). Moreover, this has the potential to encourage the integration of physical activity as part of daily lifestyle such as active travel through walking and cycling ${ }^{27}$.
Epidemiological studies also show a decrease in depressive symptoms with increasing levels of physical activity and decreasing levels of transient ${ }^{28}$. Randomized controlled trials show a causal relationship between promoting physical activity and reducing depressive symptoms in clinical and non-clinical samples ${ }^{29}$. The efficacy of exercise in reducing depressive symptoms has been established. Data on the positive mood effects of sports involvement, apart from improving fitness, show that the focus must be on the frequency of exercise rather than the duration or intensity until the behavior has been well established ${ }^{30}$.

A study related to metabolic syndrome with physical activity shows that most respondents aged over 40 years, with male sex, from the Malay ethnic group, complete secondary education and have a monthly income above RM 4000. Most respondents are obese and have moderate physical activity at the start. All variables compared between groups at baseline showed no significant difference. At six months, after the intervention there was a significant difference only in the MET score. The conclusions of the study were effective interventions in increasing physical activity among overweight and obese military personnel ${ }^{31}$.

In Indonesia, the incidence of metabolic syndrome has become a complex interaction of different including genetic, environmental and metabolic factors. Work stress factor is one of the accumulations of genetic, environmental and metabolic factors which can influence the occurrence of metabolic syndrome. There are several studies that state that there is a consistent relationship between metabolic syndrome and psychological factors such as stress, mental disorders, depression, and anxiety ${ }^{32}$

Work environment factors also have a role in causing stress factors at work. Stress factors at work are found in all workplaces. The type of work in the field to indoors has a risk for work stress factors. A number of cohort studies have been carried out on workers in the field such as the police, manufacturing plant workers, health workers in hospitals and teaching staff in the faculty area. From the results of studies that have been conducted which state that work stress factors have the potential for metabolic syndrome to occur in workers ${ }^{35}$. However, a study was found stating that there was no significant relationship between work stress and metabolic syndrome. In that study, there was no significant relationship between work stress and metabolic syndrome, but there were still many metabolic syndrome problems found in health workers. The problem of work stress is not always found to be the causative factor in the workplace, and has different levels ${ }^{36}$.

The type of work that can cause stress is a type of work that is related to time, work disruption and 
the complexity of a job. Apart from the type of work, environmental factors such as exposure to physical and verbal violence at work and workers directly involved in witnessing and experiencing can be a small exposure to stress at work ${ }^{35}$. Metabolic syndrome is a complex interaction of different including genetic, environmental and metabolic factors. Work stress factor is one of the accumulations of genetic, environmental and metabolic factors which can influence the occurrence of metabolic syndrome. There are several studies that state that there is a consistent relationship between metabolic syndrome and psychological factors such as stress, mental disorders, depression, and anxiety ${ }^{32-34}$.

The prevalence of metabolic syndrome in office workers is very high in Iran compared to other countries in the world such as China and Turkey, so the workplace is obliged to identify and prevent metabolic syndrome to improve the health status of workers. This research was conducted on office workers in Qom Province, Central Iran with a multistage cluster random sampling. Justification of metabolic syndrome is done by checking cholesterol levels (HDL), fasting blood sugar, blood pressure and waist circumference. The results show that the higher the age of the worker, the more metabolic syndrome occurs. Laboratory results show that office workers tend to have high cholesterol levels. One reason is the lack of physical activity in his spare time and low fruit intake. In addition, the average worker tends to have a BMI (Body Mass Index) that is excessively vulnerable to suffer from metabolic syndrome. Metabolic syndrome is more common in male office workers than women. Lack of physical activity in workers increases the risk of hypertension, obesity, diabetes and metabollic syndrome. Consumption of sufficient fruit can reduce the risk of metabolic syndrome in addition to its benefits as antioxidants, fiber, potassium and so forth. Therefore, it is recommended to facilitate physical activity among office workers and provide adequate fruit intake ${ }^{37}$.

Cycling workstations are tools that were created to support routine physical activity at work. Physical activity is expected to reduce the risk of sedentary behavior due to sitting too often typing in the office. This breakthrough is quite interesting because the tool can be used in conjunction with typing work. Cycling workstations can facilitate workers' physical activities without reducing performance. Routine physical activity can reduce stress levels in the work environment. In addition, metabolism can run smoothly at office workers thereby reducing the risk of developing metabolic syndrome ${ }^{38}$.

Health promotion programs in the workplace are carried out as a preventive measure that supports increased work productivity. Some health promotion activities implemented in the workplace include stress management, exercise, balanced nutrition fulfillment, weight management and counseling. The results of research in a rural southeastern Louisiana school board health promotion program (high school faculty and staff, employees of the school district) and school board members) shows that routine physical activity in the workforce can reduce work stress so that employee productivity increases. Physical activity builds resistance to stress and has a long-term effect to prevent future stress. Employees who regularly carry out physical activities with diligent exercise can reduce the risk of suffering from metabolic syndrome (high blood pressure, diabetes and high cholesterol). Routine exercise is one of the right coping stress activities. The results showed that those who routinely exercised every week proved to be more careful in choosing their intake, for example tending to reduce caffeinated and readyto-eat foods. In addition, regular exercise per week minimizes the risk of emotional disturbance in workers ${ }^{39}$.

\section{CONCLUSION}

Metabolic syndrome can occur to anyone, one of whom is an employee who works in an office. Of all the risk factors for employees studied, significant factors affecting the occurrence of metabolic syndrome are work stress and exercise habits. The less routine exercise has a risk of 58 times experiencing metabolic syndrome. Long working hours from 07.30 to 16.00 with varying levels of activity result in them rarely doing sports. It can be concluded that the metabolic syndrome occurs due to increasing age, non routine exercise and work stress. Each age increases by 1 year, the risk of metabolic syndrome increases by 1.126 times. Increasing the level of work stress increases the risk of developing metabolic syndrome by 1,146 times. The less regular exercise is, the risk of metabolic syndrome increases by 58 timesEvery increase in age accompanied by a high workload can affect the occurrence of work stress. Staff should be given opportunities to exercise on the sidelines of work by providing opportunities for regular exercise every day during working hours. In addition, recreational programs are also important to manage stress..

\section{ACKNOWLEDGEMENT}

We would like to thanks to Dean of Public Health Faculty and Dean of Vocational Faculty Airlangga University for give permit for this research. We also would like to thank Head of Human Resource and Finance Division both of Public Health Faculty and Vocational Faculty Airlangga University for her help to this study. We also thank to Erwin DyahNawawinetu, dr., M.Kes as Coordinator of Occupational Health and Safety Study Program who full support for this work and all respondents who participated in this study. 


\section{REFERENSI}

1. BadanPenelitian dan Pengembangan. Laporan Nasional Riskesdas. KementerianKesehatanRepublik Indonesia. 2019.

2. PeraturanMenteri Tenaga Kerja dan Transmigrasinomor 5 tahun 2018. Kementerian Tenaga Kerja dan Transmigrasi. 2018.

3. Tarwaka. 2015. Ergonomilndustri :Dasardasarpengetahuan ergonomic dan aplikasi di tempatkerja. Harapan Press : Surakarta

4. Vancampfort, D., Correll, C.U., Wampers, M., Sienaert, P., Mitchell, A., De Herdt, A., et al., 2014. Metabolic syndrome and metabolic abnormalities in patients with major depressive disorder: a metaanalysis of prevalences and moderating variables. Psychol. Med. 44 (10), 20172028.

5. Magnavita, N., Fileni, A., 2014. Work stress and metabolic syndrome in radiologists: first evidence. Radiol. Med. 119 (2), 142-148.

6. Chandola, T., Brunner, E., Marmot, M. 2006. Chronic stress at work and the metabolic syndrome : prospective study. BMK, doi : 10.1136/bmj.38693.435301.80

7. Mahan LK, Escott-Stump. 2008. Krause's food and nutrition therapy. St. Louis : Saunders Elsevier

8. Dwipayana,

dkk.

:PrevalensiSindromaMetabolikpadaPopula siPenduduk Bali, Indonesia. JurnalPenyakit Dalam, vol. 12 no. 1.

9. Sargowo D, Andarini S. Pengaruhkomposisiasupanmakananterhad apkomponensindrommetabolik. J Kardiollndones. 2011; 32:14

10. Kaur, J. A Comprehensive review on metabolic syndrome. Cardiol Res Prac. 2014; 943162. Available at https://www.ncbi.nlm.nih.gov/pmc/arti cles/PMC3966331/\#

11. IASO (International Association for the Study of Obesity) (2007 Adult overweight and obesity in the European Union (EU27). Available at: http://www.iotf.org/database/EU27Jun e07.htm

12. Haskell WL, Lee I-M, Pate RR et al. (2007) Physical activity and public health. Updated recommendation for adults from the American College of Sports Medicine and the American Heart Association. Circulation 116: 1081-93.

13. Alberti KG, Zimmet $P$, Shaw J; IDF Epidemiology Task Force Consensus Group. The metabolic syndrome new worldwide defnition.

Lancet2005;366:1059-62.

14. Executive summary of the third report of the NationalCholesterolEducation Program (NCEP)ExpertPanelondetection, evaluation and treatment of high blood cholesterol in adults (Adult Treatment Panel III). JAMA 2001;285:2486-97

15. Damayanti, R., NawawinetuD.Erwin. Determinant Factors of Work Stress Among Teaching and Non-Teaching Staff In Indonesia. Indian Journal of Public Health Research \& Development. Volume 10, Number 3, March 2019

16. Ranasinghe $\mathrm{P}$, Mathangasinghe $\mathrm{Y}$, Jayawardena R, Hills AP, Misra A. Prevalence and trends of metabolic syndrome among adults in the asia-pacific region: a systematic review. BMC Public Health [Internet]. 2017;1-9. Available from: http://dx.doi.org/10.1186/s12889017-4041-1

17. Institute For Health Metric And Evaluation. The Global Burden Of Disease: Generating Evidence, Guiding Policy. USA; 2010.

18. Herningtyas, Elizabeth $\mathrm{H}$. Prevalence and distribution of metabolic syndrome and its components among provinces and ethnic groups in Indonesia. BMC Public Health [internet]. 2019;1-12.

19. Rosmond R. Role of stress in the pathogenesis of the metabolic syndrome. Psychoneuroenocrinology 2005; 30:1-10.

20. Selye H. The stress of life. New York: McGraw-Hill; 1975

21. Hjemdahl P. 2002. Stress and Metabolic Syndrome (An interesting but Enigmatic Association). American Heart Association Journal 106:2634-2636 cited from http://ahajournals.org December 16,2019 .

22. Anagnotis, P; Athyros Vasilios G., Tziomalos, K., Karagiannis, A., Mikhailidis, D P. The pathogenetic role of cortisol in the metabolic syndrome : a hypothesis. J Clin Endocrinol Metab, August 2009, 94 (8):2692-2701 
23. Pasquali R, Vicennati V, Cacciari $M$, Pagotto U $2006 \quad$ The hypothalamicpituitary-adrenal axis activity in obesity and the metabolic syndrome. Ann NY AcadSci 1083:111-128

24. Walker BR. 2006. Cortisol-cause and cure for metabolic syndrome? DiabetMed 23:1281-1288

25. Garbarino S, Magnavita N. Work Stress and Metabolic Syndrome in Police Officers . A Prospective Study. PLosOne.2015 Dec 7;10(12):e0144318.

26. Janczura M, Bochenek G, Nowobilski R, Dropinski J. The Relationship of Metabolic Syndrome with Stress, Coronary Heart Disease and Pulmonary Function - An Occupational Cohort-Based Study. 2015;1-20.

27. WHO. 2010. Global recommendations on physical activity for health. Switzerland : WHO Press

28. Schuch, F., Vancampfort, D., Firth, J., Rosenbaum, S., Ward, P., Reichert, T., et al., 2017. Physical activity and sedentary behavior in people with major depressive disorder: a systematic review and metaanalysis. J. Affect. Disord. 210, 139-150.

29. Wiernik, E., Meneton, P., Empana, J.-P., Siemiatycki, J., Hoertel, N., Vulser, H., et al., 2018. Cardiovascular risk goes up as your mood goes down: Interaction of depression and socioeconomic status in determination of cardiovascular risk in the CONSTANCES cohort. Int. J. Cardiol. 262, 99-105.

30. Craft, Lynette L; Perna, Frank M. The benefit of exercise for clinically depressed. J Clin Psychiatry 2004: 6 (3).

31. Fuad, AFA, Ismail S, Rahman HA.Effect of Physical Activity Intervention on Physical Activity, Body Mass Index, Blood Pressure, Blood Lipid and Fasting Blood Sugar Among Overweight and Obese Military Personnel. Mal J Med Health Sci 15(SP3): 8-14, Nov 2019.

32. Mitchell, Ale J., Davy Vancampfort2, Kim Sweers3, Ruud van Winkel3, Weiping Yu3 and $\mathrm{MDH}$. Prevalence of Metabolic Syndrome and Metabolic Abnormalities in Schizophrenia and Related Disorders - A Systematic Review and Meta-Analysis. 2013;39(2):306-18.

33. Pan An , Mika Kivimaki P, Nana Keum M, Richard R. Rubin P, et al. Bidirectional Association Between Depression and
Metabolic Syndrome. Diabetes Care. 2012 May; 35 (5) : 1171-80

34. Nishina M, Nishina K, Ohira T, Makino K, Iso $H$. Associations of Psychological Distress with Metabolic Syndrome Among Japanese Urban Residents. 2006;396-402.

35. Magnavita N. Work-Related Psychological Injury Is Associated with Metabolic Syndrome Components in Apparently Healthy Workers. PLosOne.2015 Jun 18 ; 10 (6):e0130944.

36. Niazi E, Saraei M, Aminian O, Izadi N. Diabetes \& Metabolic Syndrome : Clinical Research \& Reviews Frequency of metabolic syndrome and its associated factors in health care workers. Diabetes Metab Syndr Clin Res Rev [Internet]. 2019;13(1):338-42. Available from: https://doi.org/10.1016/j.dsx.2018.10.0 13

37. Alavi, SS., Makarem, J, Mehrdad R, Abbasi M. Metabolic Syndrome: A Common Problem among. 2015;6:34-40.

38. Elmer SJ, Martin JC. A cycling workstation to facilitate physical activity in of fi ce settings. Appl Ergon [Internet]. 2014;45(4):1240-6. Available from: http://dx.doi.org/10.1016/j.apergo.201 4.03.001

39. Gillan W, Naquin M, Zannis M, Bowers A, Brewer J, Russell S. Correlations among Stress, Physical Activity and Nutrition: School Employee Health Behavior. 2010;8(1):55-60. 